\title{
MontanAqua: Tackling Water Stress in the Alps Water Management Options in the Crans-Montana-Sierre Region (Valais)
}

\begin{abstract}
Transdisciplinary research is considered an appropriate mode of knowledge production in the search for pathways towards a more sustainable governance of natural resources. However, the co-production of new knowledge between scientists of different disciplines and nonacademic stakeholders
\end{abstract}

is a challenge that requires novel research designs, methods, and approaches. The MontanAqua team has tackled this challenge by designing and implementing an innovative process of co-production of knowledge. An important element of this process was an assessment and communication tool known as "the sustainability wheel".

Flurina Schneider, Mariano Bonriposi, Olivier Graefe, Karl Herweg, Christine Homewood, Matthias Huss, Martina Kauzlaric, Hanspeter Liniger, Emmanuel Rey, Emmanuel Reynard, Stephan Rist, Bruno Schädler, Rolf Weingartner

MontanAqua: Tackling Water Stress in the Alps. Water Management Options in the Crans-Montana-Sierre Region (Valais) GAIA 25/3 (2016): 191-193 | Keywords: climate change, future visions, sustainable water management, transdisciplinarity, water availability, water use

\section{How the Project Was Organized}

Climate and socio-economic changes will alter the distribution of water resources and water use in the coming decades, particularly in dry Alpine areas with dynamic economic, tourism, and urban development. Coping with these changes will require a fundamental rethink of current water management arrangements. Against this background, the overall objective of the MontanAqua project ${ }^{1}$ was to develop, in cooperation with regional stakeholders, sustainable water management strategies to cope with possible future water scarcity in the Crans-Montana-Sierre (Valais, Switzerland) region.

To achieve this goal, we studied water-related problems and solutions from a transdisciplinary perspective (figure 1, p. 192). The research was divided into three work packages (WPs) and one synthesis package. In WP1, available water resources were measured and modelled in and for the different altitudinal zones. In WP2, we evaluated water use including drinking water, energy production, agriculture, viticulture, and tourism. Decision-making related to water use was studied in WP3 through an analysis of the socio-economic structure from the communes to the canton. The synthesis package investigated the links between the three WPs, created methods for inter- and transdisciplinary knowledge production, and designed and organized processes of stakeholder involvement.

1 One of the 16 research projects of the Swiss National Research Programme on Sustainable Water Management (NRP 61), funded by the Swiss National Science Foundation (SNSF).

\section{Transdisciplinary Approach}

We understand transdisciplinary co-production of knowledge as a process in which scientists, experts, and other nonacademic stakeholders co-construct systems, target, and transformation knowledge with a view to finding solutions to concrete life-world problems related to sustainable development. In this process, scientific work is regarded as part of an overall societal learning process involving various societal actors (Pohl and Hirsch Hadorn 2007, Schneider 2011).

In our project, transdisciplinary collaboration started with a broad stakeholder meeting in November 2008 to jointly frame the relevant problems and goals to be addressed by the project. Afterwards, the stakeholder group RegiEau was set up to bring together all stakeholders involved in water management (representatives of hydropower, viticulture, agriculture, tourism, environment, communes, and the canton). This group regularly met with researchers throughout the research process (twelve times) to discuss upcoming issues and jointly generate new knowledge.

The research team first analysed current water availability and use, as well as current water management in the region's eleven municipalities (systems knowledge). This information was used

Contact: PD Dr. Flurina Schneider | University of Bern | Centre for Development and Environment (CDE) | Hallerstr. 10 | 3012 Bern | Switzerland | Tel.: +41316315582 | E-Mail: flurina.schneider@cde.unibe.ch

(C) 2016 F. Schneider et al.; licensee oekom verlag. This is an Open Access article distributed under the terms of the Creative Commons Attribution License (http://creativecommons.org/licenses/by/3.0), which permits unrestricted use, distribution, and reproduction in any medium, provided the original work is properly cited. 
as the basis for an examination of possible evolutions of the water system up to 2050. The current situation was investigated via glaciological, hydrogeological, and hydrometeorological measurements and model calculations, as well as documentary, statistical and interview/focus group-based analyses. When modelling the future, the research team considered regional climate scenarios as well as four scenarios - derived from collaboration with regional stakeholders - of possible societal and economic development. Participatory scenario development was an important boundary activity that allowed stakeholders and researchers to exchange knowledge and jointly work towards the overall project objective. Moreover, stakeholders representing very different interests elaborated a common vision as a basis for future sustainable regional development (target knowledge). Based on these assessments, strategies for sustainable water management were developed (transformation knowledge) (for more details see Reynard et al. 2014, Schneider et al. 2014).

In addition, the researchers elaborated the sustainability wheel - an innovative method for structuring complex, heterogeneous knowledge (figure 2) (Schneider et al. 2014). The sustainability wheel allowed them to gain a holistic and comprehensive perspective on water sustainability, which they were then able to communicate to the broader stakeholder audience. This approach combines the transparent identification of sustainability principles, their regional contextualization through sub-principles (indicators), and the scoring of these indicators through deliberative dialogue within an interdisciplinary team of researchers, taking into account their various qualitative and quantitative research results.

Furthermore, to explore the relevance of the case study research for other regions, we established a "transfer group" comprising representatives of other water-scarce alpine regions (Italy, Austria, France, Switzerland). Finally, to assess the benefits of the transdisciplinary approach, we systematically monitored and assessed the related processes and outcomes.

\section{Key Messages for Stakeholders}

In view of the four scenarios, the results were presented to regional stakeholders as five key messages (Weingartner et al. 2014):

- By 2050, the effects of societal and economic change will have a stronger influence on the water situation than climate change will. Therefore, a territorial development plan that limits water needs is recommended.

- Overall, the annual available water volumes are sufficient for today's needs as well as those expected in 2050. However, local and seasonal (e.g., second half of summer) water shortages

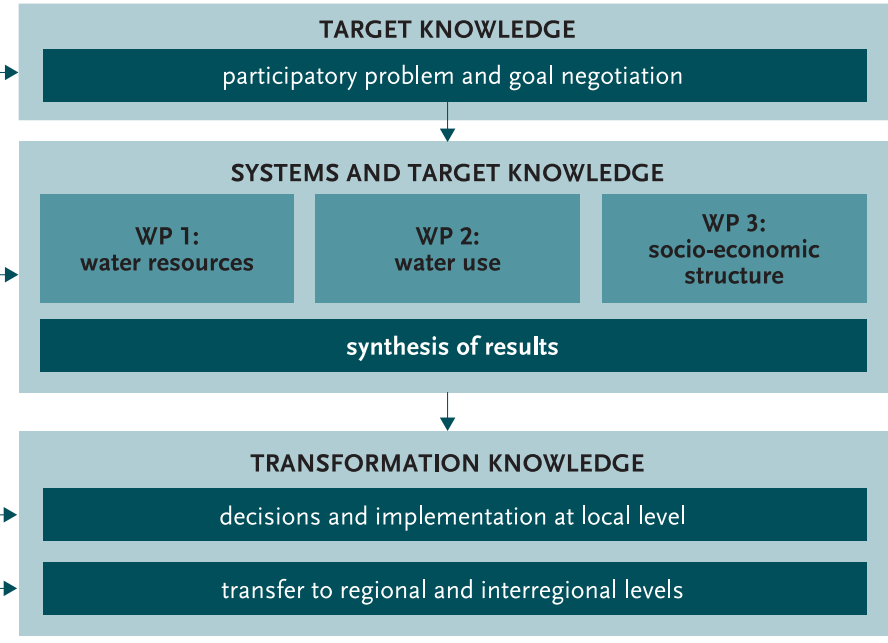

FIGURE 1: Framework of the MontanAqua project. Collaborating with the researchers throughout the , the two stakeholder groups TRANSFER and RegiEau played an important role in the transdisciplinary co-production of knowledge. Dark green denotes a high level of stakeholder involvement; lighter green denotes a lower level.

are to be expected. Therefore, regional water management involving all communes must be encouraged.

- Water issues are primarily regional management problems. To reduce the need for water and to coordinate water use, there is a need for improved cooperation between municipalities and for policy change towards demand management.

- Inter-communal measures on infrastructures can help ensure sustainable water supply, but only if they are integrated with ambitious institutional reforms. More equitable water distribution requires a realignment of the water management institutions to encompass the well-being of the entire population. In particular, water access rights need to be renegotiated.

- To achieve sustainable regional water management, improved data management and transparency is needed. The canton should draft a strategy for monitoring the water situation, regularly assessing the sustainability of water management practices at a regional level, and studying the legal situation.

\section{Benefits of the Transdisciplinary Approach}

Benefits of the transdisciplinary approach were assessed through a one-day workshop with the whole research team and a series of qualitative interviews by a BSc student with members of the stakeholder group RegiEau. These assessments led to identification of the following three main benefits:

Transdisciplinary collaboration allowed us to

1. grasp the complexity of the regional water situation and create a holistic understanding of sustainability problems and possible solutions (e.g., to assess biophysical and social dimensions of water sustainability). Both natural and social scientists valued learning about and integrating insights from other disciplines. 


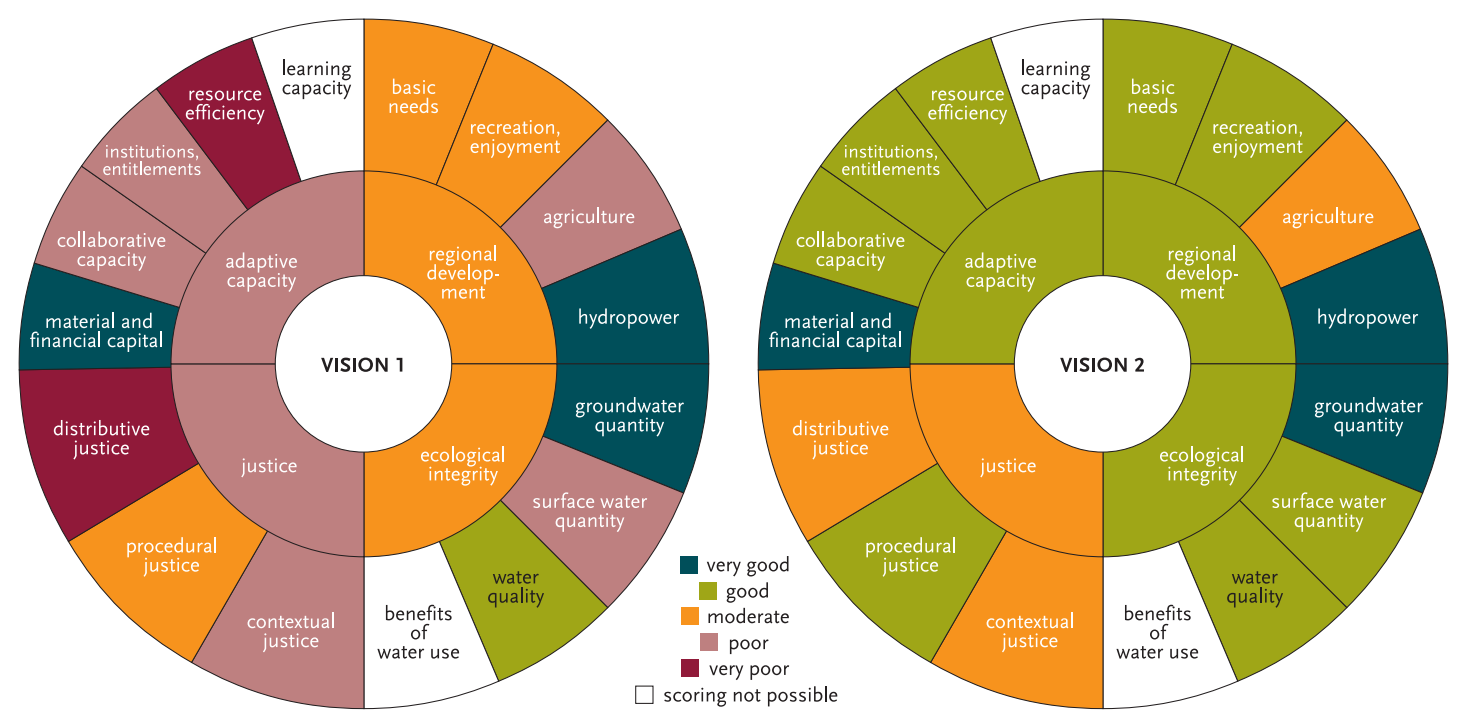

FIGURE 2: Sustainability wheels for water governance system in Crans-Montana-Sierre: two future scenarios for 2050. The inner circle shows the four main principles of sustainable water governance; the outer circle presents the indicators that specify each principle. According to the traffic light colour system, dark red denotes very poor, yellow moderate, dark green very good sustainability. Sustainability declines in Vision 1 and improves in Vision 2 (Schneider et al. 2014).

2. acknowledge the contested nature of water sustainability, including the various water-related interests, and to facilitate dialogue on more sustainable water futures among various stakeholders. The process of participatory vision development was particularly valued by the stakeholders, as well as the fact that their own visions were used to model possible future scenarios.

3. elaborate and discuss water management options, which are relevant and meaningful for regional stakeholders. Although societal impacts of the research are not easy to attribute, we can today observe several developments in the region, which are in line with the project's recommendations (e.g., foundation of a regional water association).

Overall, the research team was very satisfied with the transdisciplinary approach. As a result, different team members refined the approach and applied it to several other research and implementation projects. Moreover, we are engaged in systematically evaluating to what extent different transdisciplinary approaches effectively contribute to more sustainable development.

\section{References}

Pohl, C., G. Hirsch Hadorn. 2007. Principles for designing transdisciplinary research. Munich: oekom.

Reynard, E. et al. 2014. Interdisciplinary assessment of complex regional water systems and their future evolution: How socioeconomic drivers can matter more than climate. Wiley Interdisciplinary Reviews: Water 1: $413-426$.

Schneider, F. 2011. Approaching water stress in the Alps: Transdisciplinary co-production of systems, target and transformation knowledge. In: Managing alpine future II: Inspire and drive sustainable mountain regions. Proceedings of the Innsbruck Conference, November 21-23, 2011. Edited by A. Borsdorf, J. Stötter, E. Veulliet. IGF-Forschungsberichte 4. Vienna: Verlag der Österreichischen Akademie der Wissenschaften.

Schneider, F. et al. 2014. Assessing the sustainability of water governance systems: The sustainability wheel. Journal of Environmental Planning and Management 58/9: 1577-1600.
Weingartner, R. et al. 2014. MontanAqua: Wasserbewirtschaftung in Zeiten von Knappheit und globalem Wandel. Wasserbewirtschaftungsoptionen für die Region Crans-Montana-Sierre im Wallis. Forschungsbericht des Nationalen Forschungsprogramms NFP61. Bern: NFP61.

Submitted July 11, 2016; revised version accepted July 27, 2016.

CONTRIBUTING AUTHORS

PD Dr. Flurina Schneider, Dr. Karl Herweg, Dr. Hanspeter Liniger, Prof. Dr. Stephan Rist all: University of Bern, Centre for Development and Environment, Bern, Switzerland

PD Dr. Flurina Schneider, Dr. Martina Kauzlaric, Prof. Dr. Emmanuel Rey, Dr. Bruno Schädler, Prof. Dr. Rolf Weingartner all: University of Bern, Department of Geography and Oeschger Centre for Climate Change Research, Bern, Switzerland Prof. Dr. Olivier Graefe, Christine Homewood, MA, MSc, Dr. Matthias Huss all: University of Fribourg, Geography Unit, Department of Geosciences, Fribourg, Switzerland Dr. Mariano Bonriposi, Prof. Dr. Emmanuel Reynard both: University of Lausanne, Institute of Geography and Sustainability, Lausanne, Switzerland

\section{Flurina Schneider}

Born 1976 in Biel, Switzerland. PhD 2008. Habilitation 2016. Research at the Centre for Development and Environment (CDE), Bern; the Research Institute of Organic Agriculture (FiBL), Frick, both Switzerland; and the School of Sustainability, Arizona State University, Tempe, AZ.

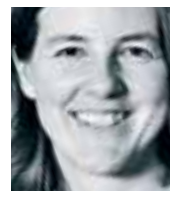

Research interests: sustainability, justice, social learning, transdisciplinary and transformative research.

\section{Rolf Weingartner}

Born 1954 In Zug, Switzerland. Since 2003 professor for hydrology at the University of Bern, Switzerland.

Research interests: mountain water resources, climate change and hydrology, floods (modelling, hazards and risks), regional hydrology (Switzerland, Alps,

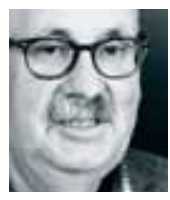

New Zealand), inter- and transdisciplinary approaches. 